\title{
A Framework for Understanding Waste Management Studies in Construction
}

Weisheng Lu and Hongping Yuan

\begin{abstract}
During the past decades, construction and demolition (C\&D) waste issues have received increasing attention from both practitioners and researchers around the world. A plethora of research investigating a wide range of topics on $C \& D$ waste management (WM) has been published in scholarly journals. The aim of this paper is to develop an intuitive framework to help understand the state of the art of the C\&D WM research. First, papers highly related to C\&D WM are retrieved and filtered based on a set of logical procedures. Second, the information including titles, keywords and abstracts of these papers is analyzed with the assistance of the Qualitative Social Research (QSR) software NVivo. Third, a framework for understanding C\&D WM research is presented based on the analytic results. By following the framework, previous research on C\&D WM is reviewed and research gaps are identified. Findings suggest that the development of effective C\&D WM strategies should base upon the whole lifecycle thinking and motivate the participation of all project stakeholders involved. Meanwhile, future research should be conducted by envisaging the multidiscipline characteristic of C\&D WM.
\end{abstract}

\section{Keywords}

Construction and demolition waste; waste management; NVivo, literature review 


\section{Introduction}

While acknowledging its significant contribution to the development of the whole society, the construction industry has also been perceived as a major contributor to environment degradation (Bossink and Brouwers, 1996; Faniran and Caban, 1998; Poon et al., 2004a). Its negative impacts on the surroundings mainly include land depletion and deterioration, energy consumption, solid waste generation, dust and gas emission, noise pollution, and consumption of non-renewable natural resources (Ofori, 1992; Sjostrom and Bakens, 1999; Chen et al., 2000; Shen et al., 2007). Since the early 1980s, with the increasing recognition of sustainable development as a new value (WCED, 1987), solid waste in the construction industry (generally termed as “construction and demolition (C\&D) waste”) has received widespread attentions around the world. A plethora of research has thus been published in various scholarly journals for investigating a wide range of C\&D waste management (WM) topics.

In view of the many studies and their wide range of coverage, an intuitive framework integrating major C\&D WM research is becoming an aspiration to be satisfied. With the help of such a framework, practitioners can easily understand current research achievements in the area without having to go through all related studies. Researchers may be in a better position to launch new studies to investigate $C \& D W M$ issues while avoiding duplication of research effort. In addition, in spite of the many publications and their wide range of coverage, a critical review of the C\&D WM research is somehow absent. 
The aim of this research is the development of an intuitive framework for understanding the state of the art of the C\&D WM studies as archived in various scholarly journals. The paper comprises of four parts. First it outlines the methodology for producing the framework. Second, a section is developed to briefly demonstrate the framework. Next, by following it, the authors critically review the major C\&D WM topics integrated into the framework. Lastly, conclusions are drawn. It is anticipated by using the framework, readers including both practitioners and researchers can quickly grasp a general picture of the C\&D WM research published in major scholarly journals during the surveyed period. More importantly, it could reveal research gaps worthy of attention and thus inspire new research directions for the future.

\section{Research methodology}

A quick browse of existing literature exhibits that a large number of articles highly concerning C\&D WM have been published over the past decades. This inspires the authors to firstly engender an intuitive framework integrating major topics for $C \& D$ WM research. Then a critical review on the publications was conducted based on the framework. It is worth highlighting that considering the comprehensiveness and reliability of research topics included in the framework will greatly influence the effective conduct of the literature review, four logical procedures are devised to give birth to the framework. 


\section{Brainstorming session}

It is important to define a boundary for C\&D WM research first so that articles related to this discipline can be effectively identified and included for further analyses. In this study, the boundary is fenced by a group of main topics; if a paper relates to the topics, it will be included for analysis. In view of the diversified coverage of C\&D WM research topics, brainstorming is considered an effective way to derive the main ones. It helps generate a large number of ideas, and by consolidating them a group of main topics can be obtained to form the boundary of C\&D WM research.

The brainstorming group consisted of 5 researchers, each with 2 to 7 years' research experience on C\&D WM. The brainstorming session was conducted on 6th April, 2009 and lasted about 40 minutes. The aim of the session was to reveal the key research topics in C\&D WM research. All attendees were informed of the objective of brainstorming at the onset of the session to enhance its efficiency. All the main ideas emerging during the brainstorming process were merged onto a large idea map. The process was facilitated with the assistance of the MindGenius, a graphical thinking software tool. Similar topics were consolidated and an idea map depicting all identified topics was shown in Figure 1.

$<<$ Insert Figure 1 here $>>$ 


\section{Retrieving and filtering papers}

The work was commenced with the identification of internationally renowned scholarly journals that have published works on C\&D WM. Based on the knowledge of the authors, three journals including the Waste Management (WM), the Waste Management \& Research (WM\&R), and the Resources, Conservation and Recycling, were selected at the first stage. The three journals particularly focus on waste management and publish works on C\&D WM occasionally. Bearing in mind the boundary developed in the above section, articles were identified by manually searching each journal issue by issue published. Soon the authors decided to investigate a reasonably limited period of 15 years from 1994 to 2008 in view of the large number of the publications over the past decades. This effort resulted in 55 papers identified for further analysis.

Afterwards, the keywords drawn from the identified 55 papers were ranked according to their frequencies of occurrence (FoC). The most frequently appeared keywords are construction waste (14 times), demolition waste (8 times), construction and demolition waste/C\&D waste (20 times), waste management (19 times), reduce/reduction/minimization (6 times), reuse (3 times), and recycle/recycling (17 times). These were then adopted as the keywords for scanning titles, keywords, and abstracts of the articles published in other international journals. Databases used for scanning include ABI, Ei CompendexWeb, ISI Web of Knowledge, Academic Search Premier and ScienceDirect accessing via a university library. This task is specially 
enhanced by an online Construction Management Abstracts by the Association of Researchers in Construction Management (ARCOM). The website archives the full titles, authors, abstracts and keywords of articles from several leading construction management related journals. Then a brief review of the titles and abstracts of papers was conducted to filter out the papers less related to C\&D WM. Again, the boundary developed in Section 2.1 served as a filter and 44 extra papers were identified as a result.

In order to further ensure comprehensiveness, all references of the 99 papers identified were manually scanned to check whether some papers are highly related to C\&D WM but have been neglected by the 99-paper list. By this cross-referring examination, 16 additional papers were found. Finally, a total of 115 papers were identified. Table 1 shows the number of related papers published in each journal.

$$
<<\text { Insert Table } 1 \text { here }>>
$$

\section{Analyzing contents using NVivo ${ }^{\circledR}$}

The task onward is to develop a framework for understanding the state of the art of C\&D WM studies through the analysis of the 115 articles. It seems very difficult to manually analyze the contents of these articles. In view of this, the authors tried to seek the possibility to perform this with the assistance of a computerized tool. Alexa and Zuell (1999) reviewed various software programs for content analysis in terms of 
their functions, features, and limitations. When considering the appropriate tool for analyzing the above articles, it is noted that the latest released version of NVivo ${ }^{\circledR}$ (version 8.0) provides a good support for importing articles in Acrobat PDF format.

$\mathrm{NVivo}^{\circledR}$ has been designed for researchers working with very rich text-based and/or multimedia information (QSR International, 2009). Traditionally, researchers had to use a variety of paper management techniques, such as photocopies, filing cards and cabinets, and colored pens. In this way they could manage the large amounts of data they created, maintain links between the chunks of data and ensure that important ideas could always be tracked (Gibbs, 2002). This work would be easier and the resulted outcomes would be more reliable with the assistance of NVivo, since its “Code” and "Model” functions enable users to classify, sort and arrange thousands of pieces of information and examine complex relationships in the data.

The titles, keywords and full texts of identified articles were all fed into the NVivo for further analysis. Problems occurred when importing some papers that were published during the 1990s; papers of this period, although in PDF format, were actually scanned as pictures and then were transformed into PDF files. It is not possible for NVivo to recognize the words in these pictures/PDF files. To solve this problem, the authors finally decided to import the titles, abstracts and keywords of these papers into NVivo manually. 
All articles imported into NVivo in this research are called "Sources". The sources were analyzed by using the "Node" function in NVivo. A node is a collection of references regarding a specific theme. The references were gathered when we were reading through the sources, and references about the same theme were categorized into the corresponding node. This process is called "coding”. For example, when we were reading the content reporting the amount of annual $C \& D$ waste generation in a country, we could create a two-level node structure with the first level is "Generation", and the second level is "Amount". Then we could select the content and code it under the “Amount” node. Following this approach, all sources can be coded paragraph by paragraph. It should be noted that preliminary codes might be iteratively modified and refined throughout the whole coding process.

After finishing coding all the sources, the relationship between the key nodes (referring to the two-level nodes in this research) could be constructed by using the “Model” function of NVivo. As shown in Figure 2, a tentative framework is generated based on the analysis of the above 115 articles using the NVivo.

$<<$ Insert Figure 2 here $>>$

In this framework, various shapes are used for representing different meanings. The diamond represents the boundary of the research, which is C\&D WM; the octagon means the strategies for $C \& D W M$, which refers to waste reduction, reuse, recycle 
and disposal; the ellipses, which comprise the majority of the framework, represent the nodes created in the coding process. A line or an arrow between any two figures indicates their inter-relationship. Particularly, a line indicates a kind of association exists between the two items connected, while an arrow indicates one item is affected by another. For instance, the line between "Waste amount" and "Waste generation" only shows that waste amount is a reflection of waste generation, but no cause-and-effect relationship exits between them. Furthermore, each number in the framework shows the total number of papers focusing on a specific sub-topic. For example, there are two sub-topics under the topic "Waste disposal", namely, "Effectiveness of disposal legislations” and "Landfill charge”, with numbers of 2, 2 respectively. This means that of the 115 papers, 2 papers particularly focus on the effectiveness of the disposal legislation, and 2 papers mainly talk about the landfill charge issue.

\section{A framework for understanding waste management studies in construction}

Figure 3 is an illustration of the framework created from the tentative framework developed using NVivo. There are four major components in this framework: (a) a C\&D WM Hierarchy indicating generic waste management strategies according to their priority; (b) a Project Lifecycle indicating the stages that waste management can be conducted; (c) a Material Lifecycle helping trace and analyze material waste; and (d) a C\&D WM Approach Spectrum indicating that WM approaches can range from "soft" management issues to "hard" WM technologies. The components were organized like a set of gauges. In using this framework, one can switch the pointers to different angles to position an existing study. For example, research on waste concrete 
recycle technology can be simultaneously positioned as "recycle" in the C\&D WM Hierarchy, “demolition” in the Project Lifecycle, “recycle” in the Material Lifecycle, and "'hard' WM Technology" in the C\&D WM Approach Spectrum. Thus, this framework helps readers to quickly grasp a general picture of the C\&D WM research as published. In addition, by following the framework, previous research on C\&D WM can be comprehensively reviewed and thus research gaps worthy of attention can be identified.

$<<$ Insert Figure 3 Here $>>$

\section{A critical review of $C \& D W M$ studies}

\section{Defining C\&D waste}

Generally, C\&D waste is defined as the waste that arises from construction, renovation and demolition activities (Kofoworola and Gheewala, 2009). It may also include surplus and damaged products and materials arising in the course of construction work or used temporarily during the process of on-site activities (Roche and Hegarty, 2006). Fatta et al. (2003) reported that C\&D waste, depending on their origins, can be classified into four categories, namely, excavation, road planning and maintenance, demolition, and worksite waste materials. In Hong Kong, it defines that “C\&D waste is, ..., arising from various construction activities including land excavation or formation, civil and building construction, site clearance, demolition activities, roadwork, and building renovation” (Shen et al., 2004; Poon et al., 2004a; Hao et al., 2007). 
It is noticed that $C \& D$ waste as an integral term is increasingly used in literature. Whilst from the landfill's perspective it makes sense to use this term to stand for all solid wastes to be dealt with, C\&D waste is not a rigid concept to indicate their specific origins. The two waste streams are considerably different in terms of their volumes. Bossink and Brouwers (1996) reported that the annual volumes of construction waste and demolition waste in Germany were estimated at 30 million tons and 14 millions tons respectively. The U.S. Environmental Protection Agency (EPA) (2002) mentioned that the majority of C\&D waste is from demolition (48\%) and renovation (44\%). An investigation in China revealed that construction practitioners viewed that construction waste is "negligible" therefore main waste management efforts should be focused on demolition waste (Li, 2006).

Research has also interpreted C\&D waste by its composition. The European Waste Catalogue (EWC) provides a comprehensive classification of C\&D waste in line with its compositions. According to it, $C \& D$ waste is classified into eight categories including (1) concrete, bricks, tiles and ceramics; (2) wood, glass and plastic; (3) bituminous mixtures, coal tar and tarred products; etc. In Hong Kong, C\&D waste is normally in the form of building debris, rubbles, earth, concrete, steel, timber, and mixed site clearance materials (Shen et al., 2004; Poon et al., 2004a; Hao et al., 2007). Although C\&D waste is often included as one of the forms of municipal solid waste (MSW), the C\&D waste is considered being heterogeneous by comparing it with the general MSW (e.g. household waste) or other industrial solid wastes (ISW) (e.g. 
hospital waste and computer waste). For example, normally the majority of C\&D waste can be reused or recycled (Tam, 2008a). Unlike household waste, C\&D waste is generated by a limited few of contractors thus it might be easier to manage. It is reported that in some developing countries, informal sector is involved in the general MSW and ISW while for C\&D waste the main involvers are contractors or specialist subcontractors (Khalil and Khan, 2009; Yuan, 2008). While research and practice often "borrow" theories and concepts (e.g. waste hierarchy, polluter pays principle) from the general waste management, the heterogeneity of $C \& D$ waste should be considered in the future study. In addition, more research to compare the characteristics of C\&D waste and other wastes is envisaged.

So far, there is a lack of consensus about the definitions of C\&D waste in literature. Different perspectives on these wastes, actually, imply different waste management philosophies. In Japan, C\&D waste is considered as construction by-product rather than waste therefore considerable efforts were given to reuse or recycle it (Nitivattananon and Borongan, 2007). In Hong Kong, the C\&D waste is divided into two major categories: inert materials and non-inert waste. Over $80 \%$ of C\&D materials including debris, rubble, earth and concrete are inert which could be used for land reclamation and site formation (EPD, 1998). The remaining is non-inert C\&D waste (e.g. bamboo, timber, vegetation, packaging waste and other organic materials) which is disposed of at landfills (EPD, 1998). Each study tends to define C\&D waste based on the characteristic of its research question. Only by defining the waste 
specifically can results of the study be meaningful for different practices.

While the above papers defined the term ' $C \& D$ waste' by viewing it as tangible wasted materials, there is another stream of research stating that $C \& D$ waste should include non-value-adding work in construction (Serpell and Alarcon, 1998). This viewpoint can be traced back to an earlier study by Skoyles (1976) who drew a distinction between direct and indirect material waste. Direct waste comprises of a complete loss of materials - this is the wasted materials mentioned by most researchers. By contrast, indirect waste refers to a monetary loss - for example, waste due to concrete slab thickness larger than specified by the structural design. This statement was also supported by Pinto’s (1989) study which found that the amount of indirect waste of mortar was as much as $85 \%$ of the designed volume of plaster. Serpell and Alarcon (1998) stated that all construction activities that produce cost, direct or indirect, but do not add value or process to the product can be called waste. Formoso et al. (2002) present the similar concept under the inspiration of industrial engineering and the Lean Production paradigm, which suggested that C\&D waste should embrace a wider view, being defined from both environmental and productivity perspectives. The definition enables researchers to consider both the material loss and the non-value-adding work. However, this belief somewhat has been overlooked by existing studies. One explanation is that wasted materials in construction are easy to see, as well as relatively easy to measure (Formoso et al., 2002). It seems that there is an imbalance of the efforts given to the investigation of 
the material loss and the non-value-adding work which should be adjusted in future studies.

\section{Measuring $C \& D$ waste}

$\mathrm{C} \& \mathrm{D}$ waste is something tangible thus triggered considerable research to measure it using quantitative approaches. Statistics from various studies have reported the amount of C\&D waste generated in different economies. It is logged that the US construction industry generated over 100 million tons of C\&D waste annually (Mills et al., 1999), and approximately $29 \%$ of solid waste in the USA is from the construction sector (Rogoff and Williams, 1994). In the UK, C\&D waste contributes more than $50 \%$ of the overall landfill volume (Ferguson et al., 1995) and 70 million tons of C\&D waste is discarded annually (Sealey et al., 2001). Craven et al. (1994) reported that construction activity generated about $20 \sim 30 \%$ of all waste entering Australian landfills. In Hong Kong, about 38\% of the solid waste comes from the construction industry (Tam, 2008a). From 1993 to 2004, the annual generation of C\&D waste in Hong Kong has more than doubled, reaching an amount of about 20 million tons in 2004 (Poon, 2007).

The above research reported the waste volumes in absolute terms, which enable the general public to realize the severity of $C \& D$ waste as a concomitant of construction activities. Research also reported the percentage of C\&D waste in the total municipal solid waste (MSW). It can be seen that amongst total MSW the C\&D waste is a major 
proportion that deserves a research discipline in its own right. C\&D WM is becoming an emerging and popular discipline. Some research tried to compare these reported percentages in order to discover the reasons leading to the high or low waste rates. For example, Tam (2008a) mentioned that C\&D waste forms $19 \%$ and $14 \%$ of the waste disposed of at landfills in Germany and Finland respectively while in Hong Kong the percent is about $38 \%$. However, these comparisons should be treated with caution because the percentage is influenced by not only construction but also other factors such as economy scale, population, territory and behaviors in generating MSW etc. Researchers have introduced waste generation rates (WGRs) as a more comparable indicator in different economics.

WGR is a variable that helps understand waste management in the construction sector. The investigation of WGR has long been attractive to researchers as well as construction practitioners. Skoyles (1976) examined WGRs for 37 materials in UK. Bossink and Brouwers (1996) investigated material waste rates in Netherland and compared them with those in other countries to identify the consequence of using different construction techniques, work procedures, and common practices. McDonald and Smithers (1998) and Formoso et al. (2002) conducted research on WGR in Australia. Poon led a series of research (e.g. Poon et al., 2001, 2004a, 2004b, 2004c), investigating WGRs for various construction materials in Hong Kong. Tam et al. (2007) assesses the WGRs affected by sub-contracting relationships and projects types with their correlations. 
Methodologies adopted for obtaining data for estimating the WGRs are diverse. These typically include direct observation (Skoyles, 1976; Poon et al., 2001; 2004a), comparing contractors' records (Skoyles, 1976), questionnaire and telephone survey (McGregor et al., 1993), sorting and weighing the waste materials on site (Bossink and Brouwers, 1996), collecting data through consultation with construction company employees (Treloar et al., 2003; Tam et al., 2007), and tape measurement and truck load records (Poon et al., 2001; 2004a). Normally, two approaches are prevailing: classifying wastes into different categories or treating them as a whole. Since Skoyles (1976) examined WGRs related to 37 materials individually, many later studies (e.g. Bossink and Brouwers, 1996; Formoso et al., 2002, Treloar et al., 2003; Tam et al., 2007) followed his approach and investigated WGRs by differentiating material wastes. Other studies (e.g. Poon et al., 2004a) investigated construction wastes without them being sorted on-site; by treating the waste stream as a whole, they derived a general rate such as volume $\left(\mathrm{m}^{3}\right)$ or quantity (tons) of waste generated per $\mathrm{m}^{2}$ of gross floor area.

Lu et al. (2009) summarized the three main functions of WGR: first, it can provide quantitative information for benchmarking different construction waste management (CWM) practices; second, it helps raise people’s awareness about WM in construction; and third, it assists contractors in developing effective CWM strategies. This echoed with Formoso et al. (2002) who suggested that WGR provides an effective way for 
assessing the performance of WM because it usually allows areas of potential to be pointed out and main causes of inefficient to be identified. By measuring C\&D WM performance based on the WGR, different C\&D WM practices can be benchmarked and effective strategies for WM can be possibly developed.

Nonetheless, the imbalanced research in developed and developing economies hindered benchmarking of these quantitative measures and their wider applications. For example, as shown in Table 2, the majority of the 115 papers are about developed countries and regions while only a small number of papers are about emerging countries. The reasons are many, i.e. incapable statistics system in developing countries, relatively less input for $R \& D$. This resonates with previous studies indicating that the effort of reporting the amount of generated C\&D waste in some developing economies is lagging behind, typically including China (Wang et al., 2008), Malaysia (Begum et al., 2007a), Turkey (Esin and Cosgun, 2007) and Thailand (Kofoworola and Gheewala, 2009). Future research is suggested to understand the status quo of $C \& D$ waste in emerging countries as a starting point to solve $C \& D$ waste problems which can actually borrow experiences from those developed economies.

$<<$ Insert Table 2 here $>>$

\section{Waste management concepts and waste management strategies}


Three "Rs"

C\&D WM research and practice have been guided by a "3Rs" principle, which is also known as the hierarchy of C\&D WM. The principle refers to the 3Rs of reduce, reuse and recycle, which classify WM strategies according to their desirability (Peng et al., 1997; Faniran and Caban, 1998). The 3Rs is meant to be a hierarchy, arranged in ascending order of their adverse impacts to the environment from low to high. Reduction is considered as the most effective and efficient method for managing $C \& D$ waste. It can not only minimize the generation of $C \& D$ waste, but also reduce the cost for waste transporting, disposal and recycling (Poon, 2007; Esin and Cosgun, 2007). As the highest priority for managing $C \& D$ waste, it is not surprising that reduction has been examined extensively by many researchers (e.g. Begum et al, 2007b; Baldwin et al., 2007; Faniran and Caban, 1998; Poon et al., 2004b; 2004c; Seydel et al., 2002; Shen et al., 2004; Lu et al., 2006; Hao et al., 2007). With potential for reducing C\&D waste effectively, these studies have developed various solutions, which can be generally summarized into five categories, encompassing: (1) reducing waste through government legislation; (2) reducing waste by design; (3) developing an effective waste management system (WMS); (4) use of low waste technologies; and (5) improving practitioners' attitudes toward waste reduction.

Reuse means using the same material in construction more than once, including using the material again for the same function (e.g. formwork in construction) (Ling and 
Leo, 2000) and new-life reuse for a new function (e.g. using the cut-corner steel bar for shelves; using the stony fraction for road base material) (Duran et al., 2006). It is the most desirable option after reduction because a minimum processing and energy use is achieved (Peng et al, 1997). When reduction and reuse become difficult, recycling is desired. Tam (2008a) summarized that recycling can offer three benefits: (a) reducing the demand for new resources; (b) cutting down transport and production energy cost; and (c) utilizing waste which would otherwise be lost to landfill sites. So far, in comparison with those of reduction and recycling, relatively fewer studies have been conducted to address issues on reuse. Two major concerns on recycling are the economic viability and acceptability of recycled materials. Typically, Tam and Tam (2006a) found that from a purely economic point of view, recycled materials are only attractive when they are competitive with virgin materials in terms of cost and quality. In contrast to common sense, the cost of virgin material is even cheaper than that of recycled materials. Besides, the general public often worries about the quality of reused or recycled materials. It has been informed by the 115 articles that a number of studies have been focused on examining the feasibility and characteristics of recycled materials in the past decades (Bianchini et al., 2005; Tam and Tam, 2006a; 2006b; Rao et al., 2007; Nunes et al., 2007; Tam, 2008b; Tam et al., 2009).

\section{Life cycle thinking (LCT)}

The thinking of C\&D WM has been extended to the whole lifecycle. Each stage throughout a project lifecycle (e.g. conception, design, construction, operation, 
renovation, and demolition) has contributions, either direct or indirect, to the effectiveness of C\&D WM (Osmani et al., 2008; Esin and Cosgun, 2007; Hao et al., 2008). Researchers have reported factors including design, contractual and procurement could also influence the generation of C\&D waste. For example, Osmani et al. (2008) estimated that approximately $33 \%$ of on-site construction waste is related directly or indirectly to design while on the other hand few attempts have being made to minimize waste during the design process. Baldwin et al. $(2007 ; 2008)$ aimed to describe how modeling information flowing in the design process might be used to evaluate design solution when seeking to reduce construction waste in high-rise residential buildings. Tam et al. (2007) demonstrated that waste generation has a direct link with sub-contracting arrangements.

The LCT in C\&D WM can be better understood by putting it into the wider context of the construction industry. The LCT has been highly promoted in the industry as a solution to its many problems such as low trust, discontinuity, fragmentation, risks, lack of sustainability, etc. After a long period of education, the LCT has now become more welcoming, evidenced by many Life Cycle Assessment (LCA) or Life Cycle Cost (LCC) methods. However, the LCT still has a long way to go. The LCT for C\&D WM will also depend on the fate of the LCT in the construction industry. As examples of LCT for C\&D WM, Craighill and Powell (1999) developed a lifecycle assessment methodology to measure the environmental, social and economic impacts of alternative methods for managing C\&D waste. Hao et al. (2007) suggested that the 
overall efficiency of C\&D WM will largely depend on how to integrate the information and processes involved in managing C\&D waste throughout a project's lifecycle.

In this critical review section, it is worth pointing out that there are two different lifecycles. One is the project lifecycle, commonly understood as a process from conception, design, construction, operation and maintenance to demolition. Hao et al.'s (2007) study adopts this concept. The other is called material lifecycle, starting from the extraction of raw materials, through processing, construction, using, and demolition and recycling, to final disposal. The concept of material lifecycle has been seen in the discussions of sustainable development and embedded energy. The study by Craighill and Powell (1999) uses this concept. Although the two lifecycles have a large degree of overlap, it seems that the material lifecycle makes more sense of the $C \& D$ waste; it helps to trace the material process and identify the potential waste areas which could be improved. For example, by mapping the waste handling processes as a specific segment of the material lifecycle, Shen et al. (2004) provided an alterative tool for assisting in planning WM procedures on site and serving as a useful vehicle to enable the comparison of different WM practices. Lu et al. (2006) optimized the waste handling process by employing mathematical models and information technology. This is resonated with a study proposing to use waste chain which seems more promising to describe the flow of materials and the generation of C\&D waste (Yuan et al., 2009). 


\section{Polluter pays principle and waste charging scheme}

Based on the "polluter pays principle" (PPP), waste charging schemes (WCS) are promulgated in many economies as an effective strategy for managing $C \& D$ waste. A WCS is devised to impose a levy on those who dispose of their C\&D waste into public landfills. Therefore it is also called landfill charging scheme or waste disposal charging scheme. The charging scheme is not only intended to provide an economic incentive for stakeholders to reduce waste but also to encourage reuse and recycling of wasted material thereby slowing down the depletion of limited landfill and public filling capacities (Hao et al., 2008). Economists give it a theoretical explanation: "the low cost of disposing of C\&D waste in landfill sites... makes it impossible for a sustainable level of recycling to occur. C\&D waste producers thus, dispose of most of their waste in landfill sites, .... Society, however, incurs the environmental costs resulting from the waste disposal. Contractors benefit from low costs for waste disposal while incurs a high environmental cost. The policy maker must thus ensure society does not incur the external cost” (Duran et al., 2006). By using the WCS, the policy maker could try to internalize the externality by ensuring that polluters (C\&D waste producers) incur the external costs (Craighill and Powell, 1999). This situation summarizes the "polluter pays principle” and inspires most modern environment legislation (Duran et al., 2006).

It can be seen from the literature that only limited research has been conducted to 
investigate the development of WCS. Research of this kind generally adopts cost-benefit analyses (e.g. Duran et al., 2006; Johnston and Mincks, 1995; Mills et al., 1999; Craighill and Powell, 1999; Begum et al., 2006). These important works outlined the belief for developing C\&D WCS - if no other legislative command and control, economic considerations have a major influence on whether conducting C\&D WM; an effective WCS should therefore grant economic viability for contractors to conduct the WM. Research has also investigated the effectiveness of these WCS. For example, in Hong Kong, since December 2005 the government has introduced a WCS (EPD, 2006). This has been reported as being effective; C\&D waste was significantly reduced after the implementation of the WCS (Hao et al., 2008; Chui, 2007). In Shenzhen, China, the current charge for dumping into landfills is about 5.88 Yuan (\$0.86) per ton (Yuan, 2008), which is much lower compared with that in other countries and regions, i.e. HK\$125 (\$16.13) per ton in Hong Kong (Hao et al., 2008).

Two debates on the radar are of particular interest. The first one is that some researchers treat the waste charge as a penalty (Tam et al., 2008a) while others treat it as an incentive (e.g. Hao et al., 2008). Actually the existence of the two different perspectives towards the same charge/levy is owing to the absence of the PPP at the very beginning. The thinking of shifting from a penalty to an incentive is not simply a rewording game but implies the way forward for the PPP; contractors should be educated that paying for pollution is an obligation thus any saving through C\&D WM could be deemed as an incentive. The second debate is that contractors are not the 
only polluter in the construction sector therefore current practice to charge contractors only is neither fair nor effective. In practice, although not commonly, the sector is seeing an extended producer responsibility (EPR) which means that subcontractors or material vendors should be responsible for the waste generated from their supplies. Theoretical research is exploring whether it will be more effective for a WCS to charge all related stakeholders of a construction project who actually contribute to C\&D waste.

Waste management: a multidisciplinary effort

The research on C\&D WM representing in the 115 articles can be understood by putting them into a "C\&D WM Spectrum" ranging from "hard" construction technologies through to "soft” WM measures. Technology, at one end of this spectrum, is often on the front line as the approaches for managing C\&D waste. For example, low waste technologies (e.g. prefabrication instead of in-situ; and use of steel formwork and falsework instead of timber ones) are introduced to reduce the C\&D waste generation. When waste is inevitably generated, new technologies are developed to reuse and recycle it if possible, such as the use of recycled aggregates for different concrete applications (Poon and Chan, 2007). Standing at the other end of this spectrum is management. Various managerial measures are developed to manage $C \& D$ waste based on the view that $C \& D W M$ is also a behavioral and social process (e.g. promoting best WM practices). With the assistant of a process description approach, Shen et al. (2004) examined the waste handling process during 
construction, and a WM mapping model incorporating the good operations was developed. Other research is falling between the two extremes by examining both technical and managerial aspects of a C\&D WM effort. For example, Jallion and Poon (2008) examined the technical, managerial, and marketing aspects of prefabrication technology in Hong Kong. Lots of research indicates that changing project stakeholders' wasteful behavior can make a significant contribution to the effective management of C\&D waste (e.g. Lingard et al., 2001; Teo and Loosemore, 2001; Begum et al., 2009). Research also shows that the awareness of practitioners significantly contributes to the reduction of C\&D waste (e.g. McDonald and Smithers, 1998).

The C\&D WM is a multidisciplinary effort needing coordinated input from different disciplines. Any waste management strategy should be considered in the framework of administrative, financial, legal, planning and engineering functions. This has been increasingly acknowledged in both waste management research and practice. Through a critical review of the existing literature, it is noticed that research on C\&D WM mainly focused on the "hard" technologies while paid scant attention to the "soft" measures or the combined approaches of the "soft" and "hard" measures. For example, how to reduce waste generation through promoting practitioner's environmental awareness by training? How to integrate the ISO 14000 and a company’s processes to truly improve WM performance? How to measure the attitudes of the stakeholders involved toward C\&D WM? Future research is recommended to investigate the 
effective WM strategies by envisaging its multidisciplinary nature.

\section{Conclusions}

This research developed an intuitive framework for understanding the state of the art of the C\&D WM studies as archived in various scholarly journals. The framework was organized like a set of gauges; in using this framework, one can switch the pointers to different angles to position an existing study. Thus it can help readers including both practitioners and researchers quickly grasp a general picture of the C\&D WM research. The NVivo showed strengths in managing and analyzing a large amount of qualitative information of research papers. The logical procedures with the assistant of NVivo were turned out to be an effective way to give birth to the framework.

By following the framework, a critical review of existing C\&D WM studies was conducted and major findings can be summarized as follows:

- Currently, the majority of research efforts have been given to the material loss in construction activities rather than the non-value-adding work as an intangible waste. Future studies should make a balance of the research efforts focusing on these two aspects.

- Waste Generation Rate (WGR) is an effective indicator for measuring C\&D waste and benchmarking C\&D WM performance in different economies. However, more research is desired in developing economies for devising 
effective C\&D WM strategies by measuring and comparing the WGRs.

- Based on the "polluter pays principle” (PPP), waste charging schemes (WCS) are promulgated in many economies to manage $C \& D$ waste. By following this thinking, it is encouraged to develop an extended producer responsibility (EPR) or even more a WCS that motivates the participation of all project stakeholders involved.

- Considerable research has been conducted to investigate individual C\&D WM strategies at a specific stage of a construction project or a material lifecycle. However, scant attention has been paid to the development of more effective C\&D WM strategies that embrace the life cycle thinking and envisage the multidiscipline nature of C\&D WM.

\section{References}

Alexa, M. and Zuell, C. (1999). A review of software for text analysis. Mannheim, Germany: ZUMA.

Baldwin, A.N., Austin, S.A., Poon, C.S., Shen, L.Y. and Wong, I. (2007). Reducing waste in high-rise residential buildings by information modeling at the design stage. Surveying \& Built Environment, 18(1), 51-62.

Baldwin, A.N., Shen, L.Y., Poon, C.S., Austin, S.A. and Wong, I. (2008). Modeling design information to evaluate pre-fabricated and pre-cast design solution for reducing construction waste in high rise residential buildings. Automation in Construction, 17(3), 333-341.

Begum, R.A., Siwar, C., Pereira, J.J. and Jaafar, A.H. (2006). A benefit-cost analysis on the economic feasibility of construction wate minimization. Resources, Conservation and Recycling, 48(1), 86-98.

Begum, R.A., Siwar, C., Pereira, J.J. and Jaafar, A.H. (2007a). Factors and values of willingness to pay for improved construction waste management - A perspective of Malaysia contractors. Waste Management, 27(12), 1902-1909.

Begum, R.A., Siwar, C., Pereira, J.J. and Jaafar, A.H. (2007b). Implementation of waste management and minimization in the construction industry in Malaysia. Resources, Conservation and Recycling, 51(1), 190-202. 
Begum, R.A., Siwar, C., Pereira, J.J. and Jaafar, A.H. (2009). Attitude and behavioral factors in waste management in the construction industry of Malaysia. Resources, Conservation and Recycling, 53(6), 321-328.

Bianchini, G., Marrocchino, E., Tassinari, R. and Vaccaro, C. (2005). Recycling of construction and demolition waste materials: a chemical-mineralogical appraisal. Waste Management, 25(2), 149-159.

Bossink, A.G. and Brouwers, H.J.H. (1996). Construction waste: quantification and source evaluation. Journal of Construction Engineering and Management, 122(1), 55-60.

Chen, Z., Li, H. and Wong, T.C. (2000). Environmental management of urban construction projects in China. Journal of Construction Engineering and Management, 126(4), 320-324.

Chui, T. (2007). Fly-tipping of Building Materials on the Rise. The Standard, 27 March.

Craighill, A. and Powell, J.C. (1999). A lifecycle assessment and evaluation of construction and demolition waste, CSERGE Working Paper WM 99-03.

Craven, D.J., Okraglik, H.M. and Eilenberg, I.M. (1994) Construction waste and a new design methodology. In Kibert, C. J. (ed.), Sustainable Construction, Center for Construction and Environment, Gainesville, FL, pp. 89-98.

Duran X., Lenihan, H. and O`Regan, B. (2006). A model for assessing the economic viability of construction and demolition waste recycling-the case of Ireland, Resources, Conservation and Recycling, 46, 302-320.

Environmental Protection Department (EPD). (1998). Monitoring of Solid Waste in Hong Kong, 1998.

Environmental Protection Department (EPD). (2006). Available at: $<$ www.info.gov.hk/wfbu/whatwehavedone/wms/cd01.htm $>$.

Esin, T. and Cosgun, N. (2007). A study conducted to reduce construction waste generation in Turkey. Building and Environment, 42(4), 1667-1674.

Faniran, O.O. and Caban, G. (1998). Minimizing waste on construction project sites. Engineering, Construction and Architectural Management, 5(2), 182-188.

Fatta, D., Papadopoulos, A., Avramikos, E., Sgourou, E., Moustakas, K., Kourmoussis, F., Mentzis, A. and Loizidou, M. (2003). Generation and management of construction and demolition waste in Greece - An existing challenge. Resources, Conservation and Recycling, 40(1), 81-91.

Ferguson, J., Kermode, N., Nash, C. L., Sketch, W. A. J. and Huxford, R. P. (1995). Managing and Minimising Construction Waste: A Practical Guide, Institution of Civil Engineers, London.

Formoso, T.C., Soibelman M.L., De Cesare, C. and Isatto, E.L. (2002). Material waste in building industry: Main causes and prevention. Journal of Construction Engineering and Management, 128(4), 316-325.

Gibbs, G.R. (2002). Qualitative data analysis: explorations with NVivo, Buckingham, Philadelphia: Open University Press.

Hao, J.L., Hills, M.J. and Huang, T. (2007). A simulation model using system dynamic method for construction and demolition waste management in Hong 
Kong. Construction Innovation, 7(1), 7-21.

Hao, J.L., Hills, M.J. and Tam, V.W.Y. (2008). The effectiveness of Hong Kong's Construction Waste Disposal Charging Scheme. Waste Management \& Research, 26(6), 553-558.

Jaillon, L. and Poon, C.S. (2008). Sustainable construction aspects of using prefabrication in dense urban environment: a Hong Kong study. Construction Management and Economics, 26(9), 953-966.

Johnston, H. and Mincks, W.R. (1995). Cost-effective waste minimization for construction managers, Cost Engineering, 37(1), 31-40.

Khalil, N., Khan, M. (2009). A case of a municipal solid waste management system for a medium-sized India city, Aligarh. Management of Environmental Quality: An International Journal, 20(2), 121-141.

Kofoworola, O.F. and Gheewala, S.H. (2009). Estimation of construction waste generation and management in Thailand. Waste Management, 29(2), 731-738.

Li, P., 2006. Integrated utilization of C\&D waste to develop circle economy. Review report by Shenzhen Construction Bureau.

Ling, Y.Y. and Leo, K.C. (2000). Reusing timber formwork: importance of workmen's efficiency and attitude. Building and Environment, 35(2), 135-143.

Lingard, H., Gilbert, G. and Graham, P. (2001). Improving solid waste reduction and recycling performance using goal setting and feedback. Construction Management and Economics, 19(8), 809-817.

Lu, M., Poon, C.S. and Wong, L.C. (2006). Application framework for mapping and simulation of waste handling processes in construction. Journal of Construction Engineering and Management, 132(11), 1212-1221.

Lu, W.S., Wang, J.Y., Hao, J.L., Li, J.R. and Ding, Z.K. (2009). An impricial investigation of waste generation rate in Shenzhen, China. Journal of Construction Engineering and Management, Under Review

McDonald, B. and Smithers, M. (1998). Implementing a waste management plan during the construction phase of project: a case study. Construction Management and Economics, 16(1), 71-78.

McGregor, M, Washburn, H. and Palermini, D. (1993). Characterization of construction site waste: Final Report, Presented to the METRO solid waste department, Portland, Oregon.

Mills, T.H., Showalter, E. and Jarman, D. (1999). A cost effective waste management plan. Cost Engineering, 41(3), 35-43.

Nitivattananon, V. and Borongan, G. (2007). Construction and demolition waste management: current practices in Asia. In: Proceedings of the International Conference on Sustainable Solid Waste Management, 5-7 September, Chennai, India. pp. 97-104.

Nunes, K.R.A., Mahler, C.F., Valle, R. and Neves, C. (2007). Evaluation of investments in recycling centers for construction and demolition wastes in Brazilian municipalities. Waste Management, 27(11), 1531-1540.

Ofori, G. (1992). The environment: the fourth construction project objective?. Construction Management and Economics, 10(5), 369-395. 
Osmani, M., Glass J. and Price, A.D.F. (2008). Architects' perspectives on construction waste reduction by design. Waste Management, 28(7), 1147-1158.

Peng, C.L., Scorpio, D.E. and Kibert, C.J. (1997). Strategies for successful construction and demolition waste recycling operations. Construction Management and Economics, 15(1), 49-58.

Pinto, T.P. (1989). Perda de materiais em processos construtivos tradicionais (Material waste in traditional construction processes). Research Rep., Federal Univ. of Sa o Carlos, Sa o Carlos (in Portuguese).

Poon, C.S. (2007). Reducing construction waste. Waste Management, 27, 1715-1716.

Poon, C.S., Chan, D., 2007. The use of recycled aggregate in concrete in Hong Kong. Resources, Conservation and Recycling, 50(3), 293-305.

Poon, C.S., Yu, A.T.W. and Ng, L.H. (2001), A Guide for Managing and Minimizing Building and Demolition Waste, The Hong Kong Polytechnic University, Hong Kong.

Poon, C.S., Yu, A.T.W., Wong, S.W. and Cheung, E. (2004a), Management of construction waste in public housing projects in Hong Kong. Construction Management and Economics, 22(7), 675-689.

Poon, C.S., Yu, A.T.W. and Jaillon, L. (2004b). Reducing building waste at construction sites in Hong Kong. Construction Management and Economics, 22(5), 461-470.

Poon, C.S., Yu, A.T.W., See, S.C. and Cheung, E. (2004c). Minimizing demolition wastes in Hong Kong public housing projects. Construction Management and Economics, 22(8), 799-805.

QSR International. (2009). What is Qualitative Research?. Retrieved on 19-05-2009.

Rao, A., Jha, K.N. and Misra, S. (2007). Use of aggregate from recycled construction and demolition waste in concrete. Resources, Conservation and Recycling, 50(1), 71-81.

Roche, T.D. and Hegarty, S. (2006). Best practice guidelines on the preparation of waste management plans for construction and demolition projects. Available at: $<$

http://www.envirocentre.ie/includes/documents/BPGConstructionand\%20demoli tion.pdf>.

Rogoff, M.J. and Williams, J.F. (1994). Approaches to Implementing Solid Waste Recycling Facilities, Noyes, Park Ridge, NJ.

Sealey, B.J., Phillips, P.S. and Hill, G.J. (2001). Waste management issues for the UK ready-mixed concrete industry. Resources, Conservation and Recycling, 32(3-4), 321-331.

Serpell, A. and Alarcon, L.F. (1998). Construction process improvement methodology for construction projects. International Journal of Project Management, 16(4), 215-221.

Seydel, A., Wilson, O.D. and Skitmore, R.M. (2002). Financial evaluation of waste management methods: a case study. Journal of Construction Research, 3(1), 167-179.

Sjostrom, C and Bakens, W. (1999). CIB agenda 21 for sustainable construction. 
Building Research \& Information, 27(6), 347-353.

Skoyles, E.R. (1976), Materials wastage - a misuse of resources. Building Research and Practice, (July/August 1976), 232-243.

Shen, L.Y., Hao, J.L., Tam, V.W.Y. and Yao, H. (2007). A checklist for assessing sustainable performance of construction projects. Journal of Civil Engineering and Management, 13(4), 273-281.

Shen, L.Y., Tam, V.W.Y., Tam, C.M. and Drew, D. (2004). Mapping approach for examining waste management on construction sites. Journal of Construction Engineering and Management, 130(4), 472-481.

Tam, V.W.Y. (2008a). On the effectiveness in implementing a waste-management-plan method in construction. Waste Management, 28(6), 1072-1080.

Tam, 2008b. Economic comparison of concrete recycling: a case study approach. Resources, Conservation and Recycling, 52(5), 821-828.

Tam, V.W.Y., Kotrayothar, D. and Loo, Y.C. (2009). On the prevailing construction waste recycling practices: a South East Queensland study. Waste Management \& Research, 27(2), 167-174.

Tam, V.W.Y., Shen, L.Y. and Tam, C.M. (2007). Assessing the levels of material wastage affected by sub-contracting relationships and projects types with their correlations. Building and Environment, 42(3), 1471-1477.

Tam, V.W.Y. and Tam, C.M. (2006a). A review on the viable technology for construction waste recycling. Resources, Conservation and Recycling, 47(3), 209-221.

Tam, V.W.Y. and Tam, V.W.Y. (2006b). Evaluations of existing waste recycling methods: a Hong Kong study. Building and Environment, 41(12), 1649-1660.

Teo, M.M.M. and Loosemore, M. (2001). A theory of waste behavior in the construction industry. Construction Management and Economics, 19(7), 741-751.

Treloar, G.J., Gupta, H., Love, P.E.D. and Nguyen, B. (2003). An analysis of factors influencing waste minimization and use of recycled materials for the construction of residential buildings. Management of Environmental Quality: An International Journal, 14(1), 134-145.

U.S. Environmental Protection Agency (EPA). (2002). Waste Wise Update: Building for the Future. Available online at < http://www.epa.gov/wastewise/pubs/wwupda16.pdf>.

Wang, J.Y., Kang X.P. and Tam, V.W.Y. (2008). An investigation of construction wastes: an empirical study in Shenzhen. Journal of Engineering, Design and Technology, 6(3), 227-236.

WCED (World Commission on Environment and Development). (1987). Our Common Future, Oxford University Press, UK, 1-23.

Yuan, H.P., Shen, L.Y., Hao, J.L. and Lu, W.S. (2009). A model for cost-benefit analysis of construction and demolition waste management throughout the waste chain. Resources, Conservation and Recycling, under review.

Yuan, H.P. (2008). Construction and Demolition Waste Management Model Based on System Dynamics, Master thesis of Shenzhen University, China. 


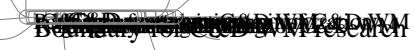

Figure 1. Research boundary for C\&D WM publications 
Table 1. Number of papers in target journals regarding C\&D WM

\begin{tabular}{ll}
\hline Journal title & No. of papers \\
\hline Resources, Conservation and Recycling & 24 \\
Waste Management & 17 \\
Waste Management \& Research & 14 \\
Construction Management and Economics & 11 \\
Building and Environment & 7 \\
Journal of Construction Engineering and Management ASCE & 7 \\
Automation in Construction & 4 \\
Engineering, Construction and Architectural Management & 4 \\
Construction Innovation & 3 \\
Management of Environmental Quality: an International Journal & 3 \\
Journal of Industrial Ecology & 3 \\
Building Research \& Information & 2 \\
Others & 16 \\
\hline
\end{tabular}




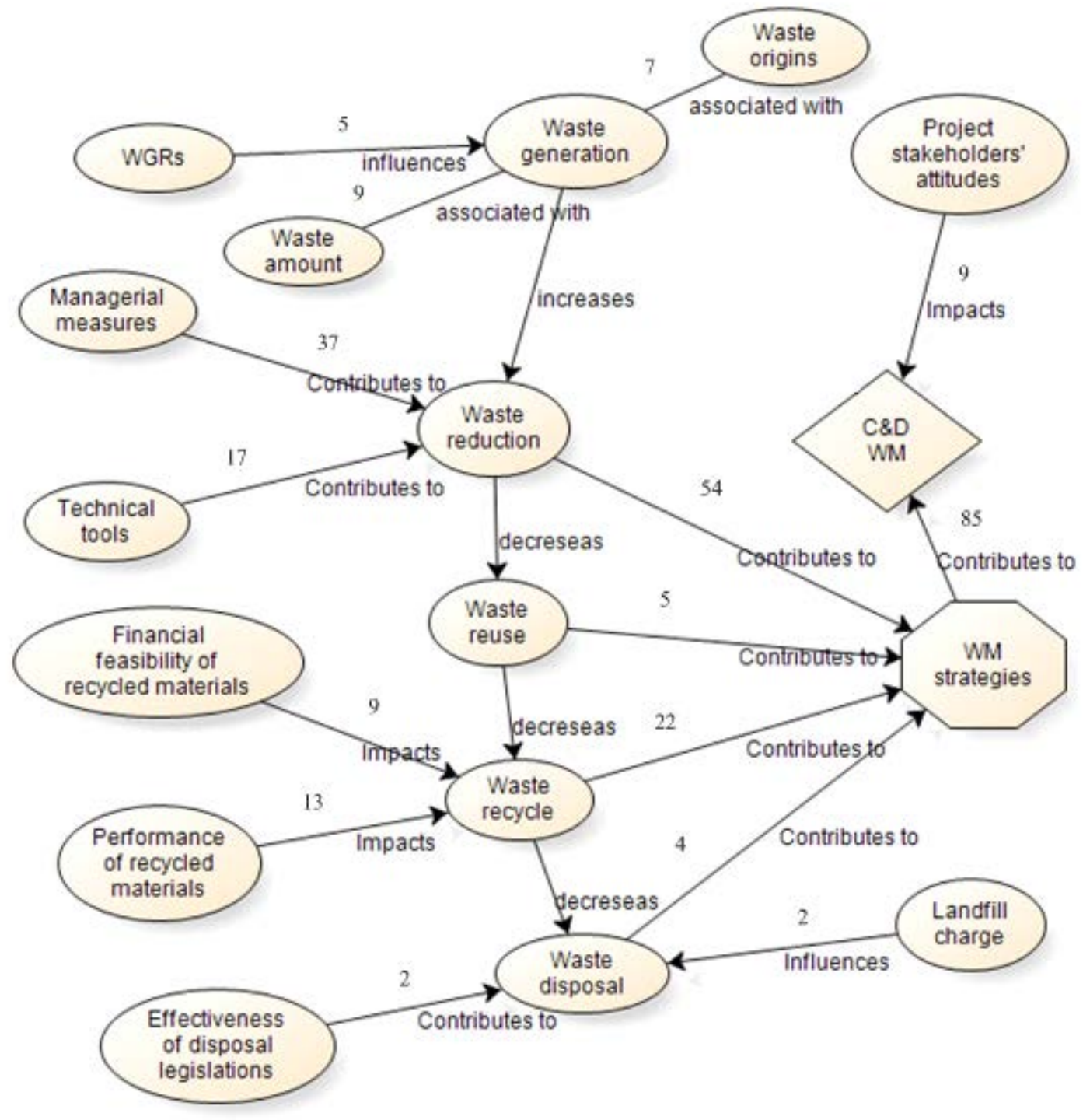

Figure 2 A tentative framework developed using NVivo 


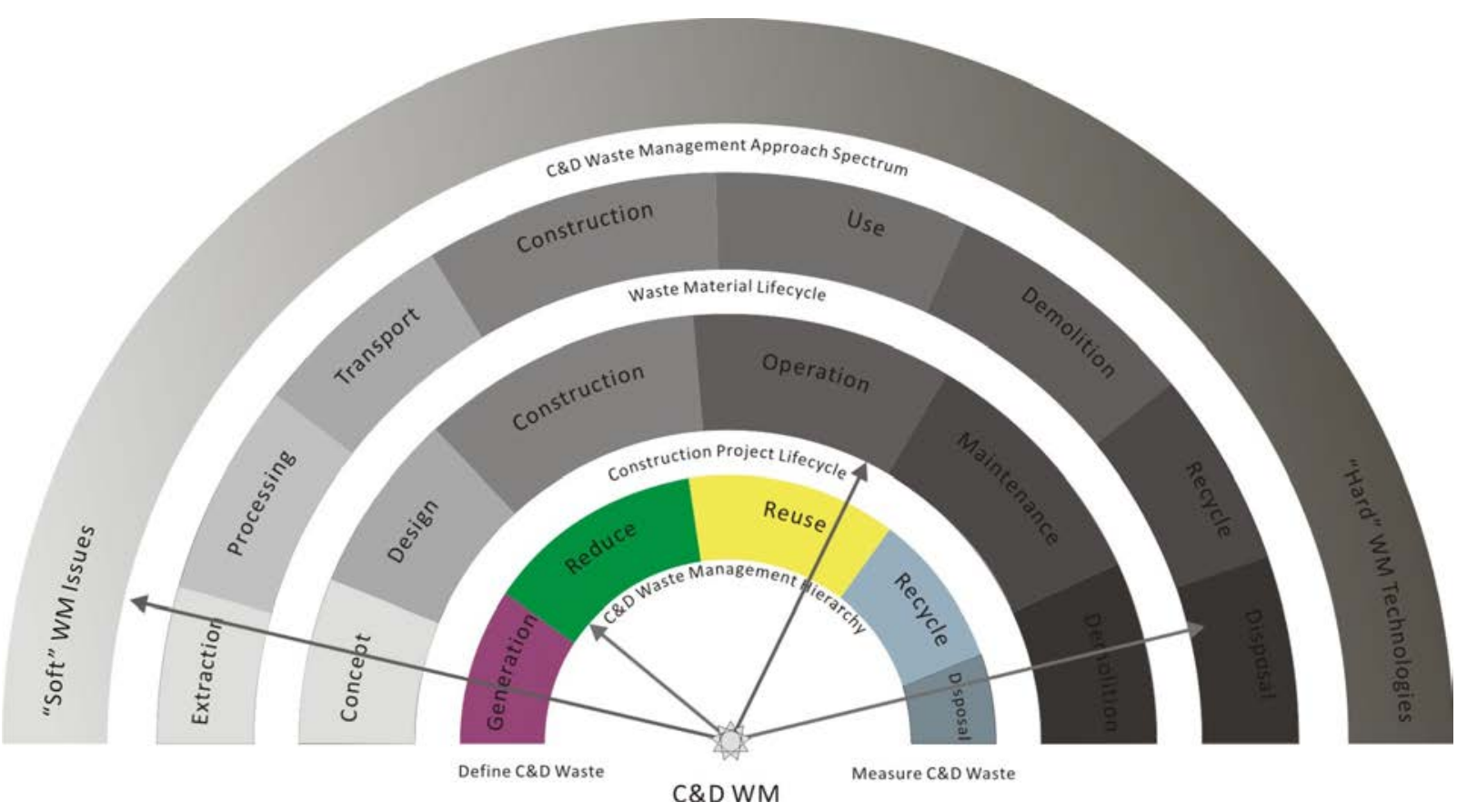

Figure 3 A C\&D waste management framework 
Table 2 A summary of reported research on C\&D waste in different economies

\begin{tabular}{|l|l|l|l|l|l|}
\hline Countries & $\begin{array}{l}\text { Number } \\
\text { of } \\
\text { papers }\end{array}$ & Countries & $\begin{array}{l}\text { Number } \\
\text { of } \\
\text { papers }\end{array}$ & Countries & $\begin{array}{l}\text { Number } \\
\text { of } \\
\text { papers }\end{array}$ \\
\hline Hong Kong & 35 & Taiwan & 2 & Kuwait & 1 \\
\hline USA & 13 & Singapore & 2 & Finland & 1 \\
\hline Australia & 10 & Netherlands & 2 & Thailand & 1 \\
\hline UK & 8 & Bulgaria & 1 & South Africa & 1 \\
\hline Malaysia & 5 & Brazil & 1 & Korea & 1 \\
\hline Germany & 4 & Cyprus & 1 & Iraq & 1 \\
\hline Sweden & 3 & Ireland & 1 & Portugal & 1 \\
\hline France & 3 & Turkey & 1 & Spain & 1 \\
\hline Norway & 3 & Sri Lanka & 1 & India & 1 \\
\hline Greece & 3 & Japan & 1 & Other & 2 \\
\hline Italy & 3 & Denmark & 1 & Total & $\mathbf{1 1 5}$ \\
\hline
\end{tabular}

